\title{
IgG4-related nephritis and interstitial pulmonary disease complicated by invasive pulmonary fungal infection: a case report
}

\author{
Yili Xu', Guang Yang', Xueqiang Xu', Yaoyu Huang ', Kang Liu', Tongfu Yu², Jun Qian', Xiufen Zhao',
} Jingfeng Zhu', Ningning Wang ${ }^{1 *}$ and Changying Xing ${ }^{1}$

\begin{abstract}
Background: IgG4-related kidney disease (IgG4-RKD) can affect multiple organs, which was first reported as a complication or extra-organ manifestation of autoimmune pancreatitis in 2004. It is characterized by abundant IgG4-positive plasma cells infiltration in tissues involved.

Case presentation: A 69-year-old man presented with cough and renal dysfunction with medical history of hypertension and diabetes. Pathological findings revealed interstitial nephritis and he was initially diagnosed with IgG4-RKD. Prednisone helped the patient to get a remission of cough and an obvious decrease of IgG4 level. However, he developed invasive pulmonary fungal infection while steroid theatment. Anti-fungal therapy was initiated after lung puncture (around cavitary lung lesion). Hemodialysis had been conducted because of renal failure and he got rid of it 2 months later. Methylprednisolone was decreased to $8 \mathrm{mg} /$ day for maintenance therapy. Anti-fungal infection continued for 4 months after discharge home. On the 4th month of follow-up, Chest CT revealed no progression of lung lesions.

Conclusions: The corticosteroids are the first-line therapy of IgG4-RD and a rapid response helps to confirm the diagnosis. This case should inspire clinicians to identify lgG4-related lung disease and secondary pulmonary infection, pay attention to the complications during immunosuppressive therapy for primary disease control.
\end{abstract}

Keywords: IgG4-Related nephritis, IgG4-Related lung disease, Corticosteroid, Invasive pulmonary fungal infection, Case report

\section{Background}

IgG4-related disease (IgG4-RD) is an inflammatory and fibrotic disease which was first described in the pancreas and was called autoimmune pancreatitis (AIP) in 2001 [1]. Its concept has been recognized worldwide since then that this systemic disease involved multiple organs or tissues characterized by elevated serum IgG4 level and IgG4 positive plasma cells infiltration in the affected

\footnotetext{
* Correspondence: wangnn@njmu.edu.cn

'Department of Nephrology, the First Affiliated Hospital with Nanjing Medical University, Jiangsu Province Hospital, Nanjing, China

Full list of author information is available at the end of the article
}

tissues, leading to fibrosis eventually [2-6]. The prevalence of IgG4-RD in Japan was estimated as $0.28-1.08$ / 100,000 people in 2012 [7].

IgG4-related tubulointerstitial nephritis (IgG4-TIN), is one of the frequent pathological changes of IgG4-related kidney disease (IgG4-RKD), accounting for about 15$25 \%$ of all IgG-RD $[4,8]$. IgG4-related TIN shows a range of histologic appearances including (A) acute interstitial nephritis with minimal fibrosis; (B) a more cellular inflammatory pattern in the setting of expansile fibrosis; and (C) a very fibrotic, pauci-cellular pattern [7]. The diagnosis criteria of IgG4-RKD were proposed

C C The Author(s). 2021 Open Access This article is licensed under a Creative Commons Attribution 4.0 International License, which permits use, sharing, adaptation, distribution and reproduction in any medium or format, as long as you give appropriate credit to the original author(s) and the source, provide a link to the Creative Commons licence, and indicate if changes were made. The images or other third party material in this article are included in the article's Creative Commons licence, unless indicated otherwise in a credit line to the material. If material is not included in the article's Creative Commons licence and your intended use is not permitted by statutory regulation or exceeds the permitted use, you will need to obtain permission directly from the copyright holder. To view a copy of this licence, visit http://creativecommons.org/licenses/by/4.0/ The Creative Commons Public Domain Dedication waiver (http://creativecommons.org/publicdomain/zero/1.0/) applies to the data made available in this article, unless otherwise stated in a credit line to the data. 
by the Japanese Society of Nephrology [9] and a work group of North America [7], respectively. IgG4-related kidney lesions were often associated with extrarenal disease, such as chronic sclerosing inflammation of the lacrimal gland, salivary gland [10] and lung [11].

Patients with IgG4-RKD have an increased risk of infection than general population. IgG4-TIN can be accompanied by eosinophilic lung disease [12] and pneumonia [13]. Here, we present a case of IgG4-RKD and lung interstitial lesions who developed invasive pulmonary fungal infection (IPFI) during treatment of glucocorticoid combined with immunosuppressive agents.

\section{Case presentation}

A 69-year-old male was admitted to the hospital in 2019 January $5^{\text {th }}$ because of gradually aggravated edema and cough. His medical history included hypertension, arrhythmia and diabetes. On 2019 May $8^{\text {th }}$, he had experienced cough and phlegm with temperature around $38 \sim 39{ }^{\circ} \mathrm{C}$. Laboratory tests were presented in Table $1 .{ }^{18} \mathrm{~F}$-FDG-PET/CT showed interstitial pneumonia in both lungs. There was also elevated uptake abnormality in the upper kidney observed. Cefperazone-Sulbactam, doxycycline hydrochloride, imipenem, and linezolid were given. Because of no improvement, he took oral prednisone $24 \mathrm{mg}$ per day. The body temperature recovered to normal and lower limb edema was alleviated after one week. On 2019 June $13^{\text {th }}$,serum creatinine 157.7 umol/L (Fig. 1); and serum albumin, 24.9 g/L. Chest computed tomography (CT) scan showed that honeycomb-like changes considering interstitial inflammation and bilateral pleural effusion (Fig. 1A).

He went to Nephrology Department on 2019 July $2^{\text {nd }}$ for further treatment. Laboratory results were presented in Table 1. Urine RBC 42.6/ul; Urine protein: creatine ratio (uPCR) $48.5 \mathrm{mg} / \mathrm{g}$; Serum IgG4 level was elevated at $3.42 \mathrm{~g} / \mathrm{L}$ (Normal range: $0.03-2.10 \mathrm{~g} /$ L). Anti-myeloperoxidase anti-neutrophil cytoplasmic

Table 1 Laboratory data performed before and after treatment

\begin{tabular}{|c|c|c|c|c|c|c|}
\hline ITEMS & $\begin{array}{l}\text { Before } \\
\text { therapy }\end{array}$ & $\begin{array}{l}\text { Steroid } \\
\text { therapy } \\
\text { for } 1 \\
\text { month }\end{array}$ & & $\begin{array}{l}\text { Steroid therapy for } \\
2 \text { months }\end{array}$ & $\begin{array}{l}\text { Steroid therapy for } \\
3 \text { months }\end{array}$ & $\begin{array}{l}\text { Steroid therapy for } \\
4 \text { months }\end{array}$ \\
\hline White blood cell count $\left.{ }^{*} 10 \wedge 9 / L\right)$ & 15.4 & 21.11 & 8.24 & & 11.66 & 13.28 \\
\hline Hemoglobin(g/L) & 129 & 108 & 84 & & 98 & 101 \\
\hline Platelet count $\left({ }^{*} 10 \wedge 9 / L\right)$ & 323 & 285 & 100 & & 273 & 176 \\
\hline C-reaction protein $(\mathrm{CRP})(\mathrm{mg} / \mathrm{L})$ & 90 & 58.1 & 32 & & 79.8 & 18.9 \\
\hline Erythrocyte sedimentation rate $(\mathrm{mm} / \mathrm{H})$ & 120 & 60 & / & & / & / \\
\hline Serum nitrogen (mmol/L) & 10.2 & 24.71 & 24.18 & & 30.33 & 14.5 \\
\hline Serum creatinine (umol/L) & 64.6 & 232.8 & 212.4 & & 187.2 & 100.7 \\
\hline Serum albumin(g/L) & 24.2 & 32 & 30 & & 27.6 & 21.2 \\
\hline Urine RBC(/ul) & / & 42.6 & 10.9 & & & 3 \\
\hline Urine protein creatine ratio(mg/g) & & 48.5 & & & & \\
\hline $24 \mathrm{~h}$ urine protein $(\mathrm{g})$ & 0.721 & 0.62 & 0.61 & & 0.45 & 0.49 \\
\hline ANCA-MPO (RU/ml) & & 35.1 & 12.7 & & 8.6 & \\
\hline ANCA-PR3 (RU/ml) & & 6.7 & 4.9 & & 4.7 & \\
\hline CD4+ / CD8 + lymphocyte & 0.81 & / & / & & / & 1.9 \\
\hline ABG & \multicolumn{4}{|c|}{ Before therapy } & \multicolumn{2}{|c|}{ Steroid therapy for 2 months } \\
\hline $\mathrm{PH}$ & \multicolumn{4}{|l|}{7.201} & \multicolumn{2}{|l|}{7.498} \\
\hline $\mathrm{PCO} 2(\mathrm{mmHg})$ & \multicolumn{4}{|l|}{20} & \multicolumn{2}{|l|}{31.6} \\
\hline $\mathrm{PO} 2(\mathrm{mmHg})$ & \multicolumn{4}{|l|}{117} & \multicolumn{2}{|l|}{49} \\
\hline $\mathrm{SpO} 2(\%)$ & \multicolumn{4}{|l|}{98} & \multicolumn{2}{|l|}{88} \\
\hline $\mathrm{K}(\mathrm{mmol} / \mathrm{L})$ & \multicolumn{4}{|l|}{5.4} & \multicolumn{2}{|l|}{4.1} \\
\hline $\mathrm{HCO}^{-}(\mathrm{mmol} / \mathrm{L})$ & \multicolumn{4}{|l|}{7.8} & \multicolumn{2}{|l|}{24.5} \\
\hline $\mathrm{BE}(\mathrm{mmol} / \mathrm{L})$ & \multicolumn{4}{|l|}{-20} & \multicolumn{2}{|l|}{1} \\
\hline
\end{tabular}



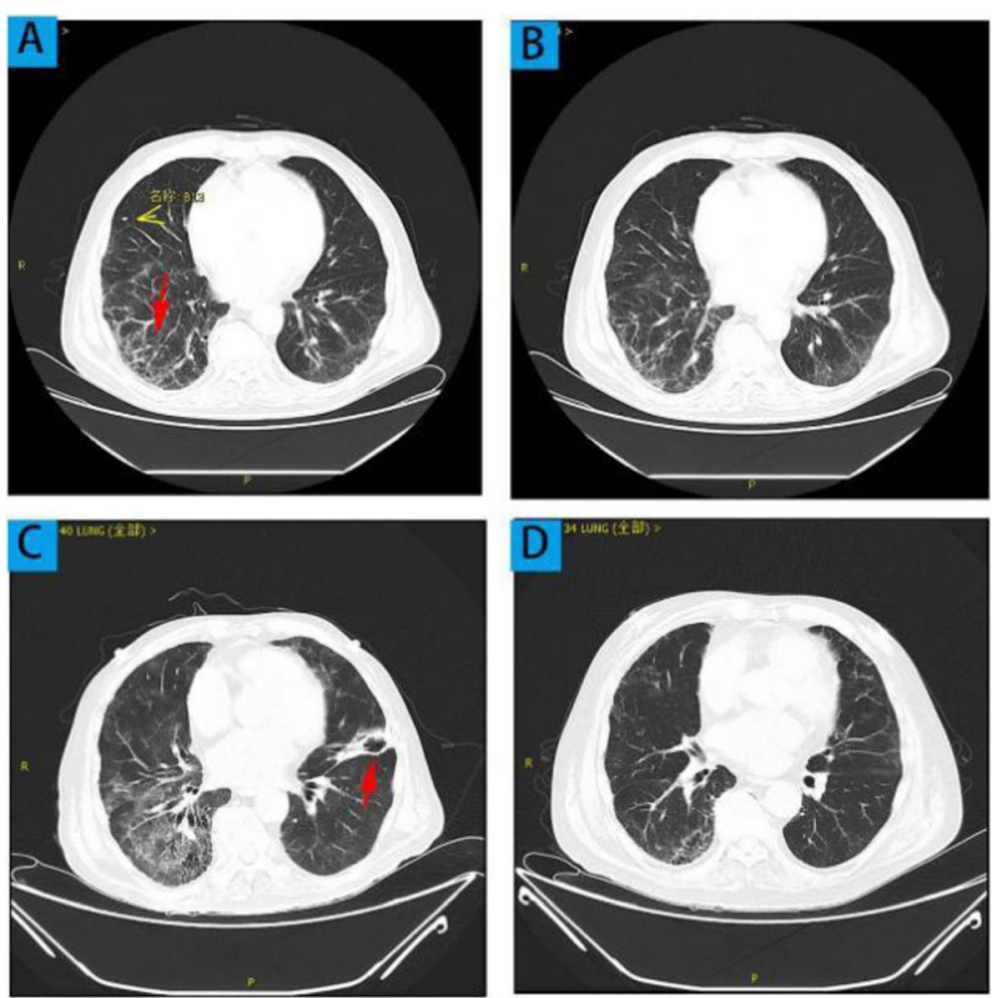

Fig. 1 Chest CT showed interstitial inflammation and bilateral pleural effusion before therapy (a). After glucocorticoids admission, obvious absorption of interstitial inflammation and pleural effusion on both sides were found (b). Infection of both lungs with a left lower lobe cavity before anti-infection therapy (c). After anti-infection therapy, no increase boarder of lung lesions (d)

antibody level was elevated at $35.1 \mathrm{Ru} / \mathrm{ml}$ (Normal range: $<20 \mathrm{Ru} / \mathrm{ml})$. However, serum immunoglobulin $\mathrm{A}(\operatorname{IgA}), \operatorname{IgG}$ and IgM level were normal. Furthermore, the patient was negative for anti-double-stranded antibody, antinuclear antibody, anti-Sjogren's syndrome A antibody, anti-Sjogren's syndrome B antibody and anti-proteinase 3. Ultrasound displayed large-sized kidneys with uniform echo frequency and clear corticomedullary boundaries. Chest CT revealed obvious absorption of interstitial inflammation and pleural effusion on both sides, there were also multiple nodules in both lungs (Fig. 1b).

Histopathology of the kidney biopsy shows proliferation of glomerular mesangial cells, diffuse and irregular thickening of basement membrane (Fig. 2a). The tubulointerstitium shows marked injury. Patchy foci fibrosis and inflammatory cells infiltration were prominent in the interstitium (Fig. 2b, c). Immunofluorescence staining shows that IgG, IgM, IgA, C1q, C3 and C4 were negative in the granular mesangial area. Immunohistological analysis revealed numerous CD20-positive B cells $((D), \times 400)$ and dense infiltration of CD138-positive plasma cells ((E), $\times$ 400 ), with an $\mathrm{IgG}^{+} / \mathrm{IgG}^{+}$plasma cell ratio being $>40 \%$ $((\mathrm{F}), \times 400)$. Electron microscopy demonstrated that there were no electron-dense deposits in the glomeruli (Fig. 3).
Based on these findings, he had been diagnosed as IgG4-related renal disease. Oral prednisone $(40 \mathrm{mg} /$ day) and cyclophosphamide (CTX, $0.4 \mathrm{~g}$ ) were prescribed by intravenous infusion. The patient had been followed up every month after the treatment (Table 1). $\mathrm{He}$ presented with intermittent fever for more than 20 days and acute onset of left pleuritic chest pain with dry cough for 10 days. Negative results were found in aerobic or anaerobic blood culture. Chest CT showed recent infection of both lungs with left upper lung cavity (Fig. 1c). At June 28th he developed hemoptysis and type 1 respiratory failure (Table 2). The results of relevant tests are shown in Table 1. In order to differentiate between IgG4-RLD and IPFI, left upper lung puncture was conducted and showed that interstitial collagen fibrosis with acute and chronic inflammatory cell infiltration, focal fibrous necrosis and exudation, and small alveolar cell response. Fungal spores were also found in lung puncture specimen. Filamentous fungi can be seen in sputum culture. Immunohistochemistry test revealed that most plasma cells in the lung interstitium were positive for CD38 (+), CD138 (+), IgG (+) (Fig. 4). IgG positive plasma cells $<40 \%$, IgG4 positive plasma cells $<10 / \mathrm{HPF}$, which does not meet the pathological 

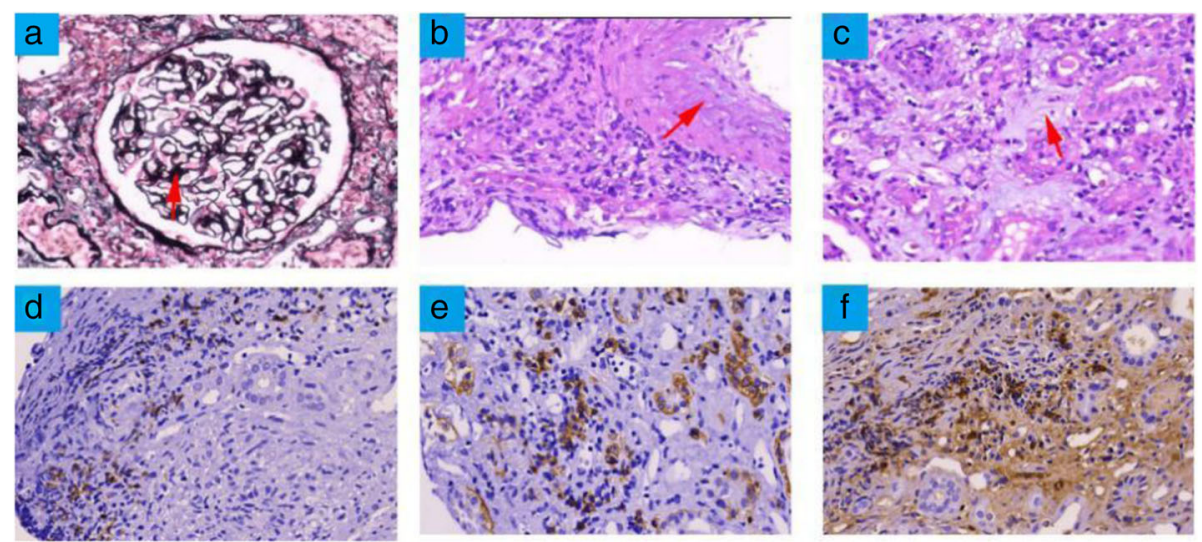

Fig. 2 Renal histopathological result showed almost normal glomeruli, massively infiltrating cells, and abundant interstitial fibrosis under the light microscopy. a The glomerulus showed glomerular mesangial cells proliferation and diffuse and irregular thickening of basement membrane (HE staining, $\times 200$ ). b, c A mass of plasma cells and fibrotic fibers (HE staining, $\times 400$ ) can be observed in the interstitium. $\mathbf{d}$, e Immunohistological analysis revealed mostly CD20-positive B cells $(\times 400)$ and CD138-positive plasma cells $(\times 400)$ in the interstitium. $\mathbf{f}$ Immunohistochemistry for IgG4 shows abundant positive plasma cells (coloured brown) $(\times 400)$

diagnostic criteria of IgG4 related diseases. The diagnosis of IPFI was definite. After then, the patient was initiated on voriconazole and caspofungin to antifungal infection, and prednisolone was decreased to $30 \mathrm{mg}$ per day.

With anti-infection and immunosuppressive treatment for 2 weeks, serum CRP and IgG4 level had been considerably decreased to $2.94 \mathrm{mg} / \mathrm{L}$ and $1.57 \mathrm{~g} / \mathrm{L}$, respectively. Voriconazole $200 \mathrm{mg}$ bid and Methylprednisolone $30 \mathrm{mg} /$ day were continued after discharge home. After treatment for one month, a repeat CT scan showed no progression of lung lesions (Fig. 1D). $\mathrm{CD}_{4}^{+} /$ $\mathrm{CD}^{+}$lymphocyte: 1.9 . The patient had been followed up for 4 months. In the most recent follow-up examination, the serum creatinine level decreased to 101 umol/L and he got rid of hemodialysis (Fig. 5). He is currently undergoing tapered prednisolone treatment.

\section{Discussion and conclusions}

This patient is characterized by serum IgG4 elevation, positive MPO-ANCA, which suggested the possibility of co-occurrence/concurrence of AAV and IgG4-RD on his first visit from his serological presentation. Diagnosis of IgG4-RD requires particular pathological, serological and clinical features [2, 14, 15] (listed in Table 2). This patient presented with serum IgG4 elevation, hematuria, proteinuria, elevated uptake abnormality of the upper kidney observed in ${ }^{18} \mathrm{~F}$-FDG-PET/CT, progressive kidney failure and interstitial lung disease. Histopathology of kidney biopsy showing typical lymphoplasmacytic infiltration and fibrosis enriched in IgG4-positive plasma cells, and infiltration of IgG4 ${ }^{+}$plasma cells with $\mathrm{IgG4}^{+} /$ $\mathrm{IgG}^{+}$plasma cells ratio greater than $40 \%$ and a total of $\geq$ 10 IgG4 $^{+}$plasma cells per high-power field (HPF) indicated the diagnosis of IgG4-RKD.

Given the elevated MPO-ANCA and CRP, AAV related nephritis was a possible differential diagnosis (Proposed diagnostic criteria for kidney involvement in AAV listed in Table 3 [16]). In this case, pathological findings did not show renal crescentic glomerulonephritis or vasculitis, thus, anti-neutrophil cytoplasmic antibody associated vasculitis (ANCA-
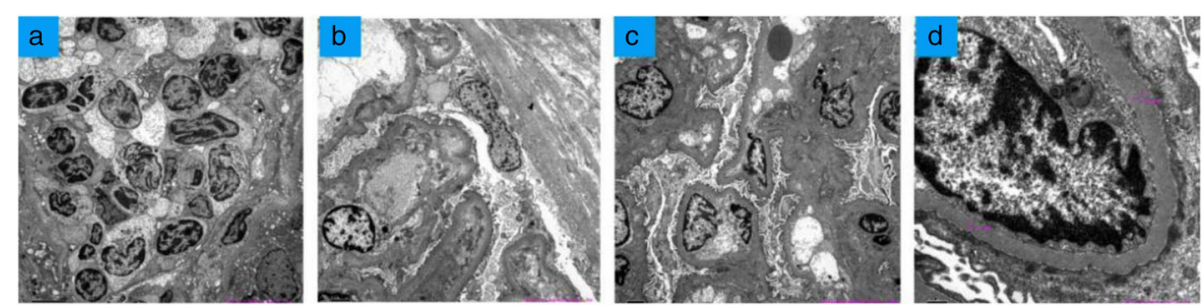

Fig. 3 No electron-dense deposits are observed under electron microscopy. a Abundant plasma cells $(\times 2000)$ infiltrated in renal interstitium. b Detachment and partial atrophy of the microvilli of renal tubular epithelial cells as well as edema, infiltration of lymphocytes/monocytes, and fibrosis in renal interstitium. There are no electron-dense deposits in the glomeruli $(\times 2000)$. c Proliferation of glomerular mesangial cells and interstitial cells $(\times 2000)$. d Diffuse and irregular thickening of basement membrane $(\times 12,000)$ 
Table 2 Proposed diagnostic criteria for IgG4-RD according to 'Comprehensive diagnostic criteria for lgG4-related disease' [2, 14, 15]

\begin{tabular}{|c|c|}
\hline Criterion & \\
\hline Histology & $\begin{array}{l}\text { (i)The specimen pathology shows the dense lymphoplasmacytic infiltrate, storiform fibrosis or obliterative phlebitis, the } \\
\text { infiltration of lgG4-positive cells, and lgG cells more than lgG4 cells ratio of } 40 \% \text {; }\end{array}$ \\
\hline Imaging & (ii)clinical/radiological examination showing characteristic diffuse or localized swelling or masses in single or multiple organs; \\
\hline Serology & $\begin{array}{l}\text { (iii) serum IgG4 concentration }>135 \mathrm{mg} / \mathrm{dL} \text {; } \\
\text { (iv)Inflammatory markers such as white blood cells count and C-reactive protein concentrations are not elevated, despite the degree of } \\
\text { lesions, their spread on imaging analysis and massive cellular infiltration on pathological examination; }\end{array}$ \\
\hline
\end{tabular}

Other organ (v)Characteristic findings of IgG4-RD in other organs, including autoimmune pancreatitis, lung involvement, et al. involvement

Treatment (vi)response to steroids.

All 3 criteria $(\mathrm{i}+\mathrm{ii}+\mathrm{iii})$ are needed for definite diagnosis of IgG4-RD

AAV) was not firstly considered according to the Chapel Hill Consensus Conference nomenclature criteria for AAV [16]; However, Some ANCA positive patients may present with interstitial nephritis without severe glomerulopathy, and whether his initial interstitial lung disease was related to IgG4 or AAV or both was not determined. Some reports suggested a possible pathogenic effect of ANCA-IgG4 [17, 18]. Serum IgG4 increase and IgG4-positive cell infiltration in the organ can also be seen in $\operatorname{AAV}[19,20]$. Distinguishing between these diseases is essential for treatment planning [20], because IgG4-RD responds well to steroid therapy alone, while AAV often requires concomitant immunosuppressant use. His initial interstitial lung disease was improved (Fig. 1) with prednisone therapy alone for one month favored the diagnosis of IgG4-RLD. Kim et al. [21] described that a steroid trial was useful for differentiating and response to steroid therapy is recommended to be added to the diagnostic criteria. Proposed diagnostic criteria for IgG4-RD according to 'Comprehensive diagnostic criteria for IgG4-related disease' listed in
Table 2. Therefore, we preferred his diagnosis of IgG4-RD.

Since kidney involvement was firstly reported in a patient with IgG4-RD in 2004 [22], many similar cases have been described [23-25]. A cross-sectional study reported in 2010 revealed all kidney lesions were associated with extrarenal disease among 114 patients with IgG4-related disease [26]. Several clinicopathologic studies reported IgG4-RD with both kidney and lung involvement [5, 14, 27-30]. In kidney its characteristic manifestation is TIN with multiple extrarenal tissue damage [14, 31], which is easily apparent with a chronic or rapid progressive renal function decline [23]. In lung, this may present as nodules with spiculated margins mimicking primary pulmonary malignancy $[28,32]$, multiple ground glass opacities (GGO) mimicking interstitial lung disease [14], alveolar interstitial type, and bronchovascular type [33].

However, he developed intermittent fever, acute onset of left pleuritic chest pain and an emerging lung lesion after steroid use for one month. IgG4-RLD has been classified into four categories based on CT. Our case

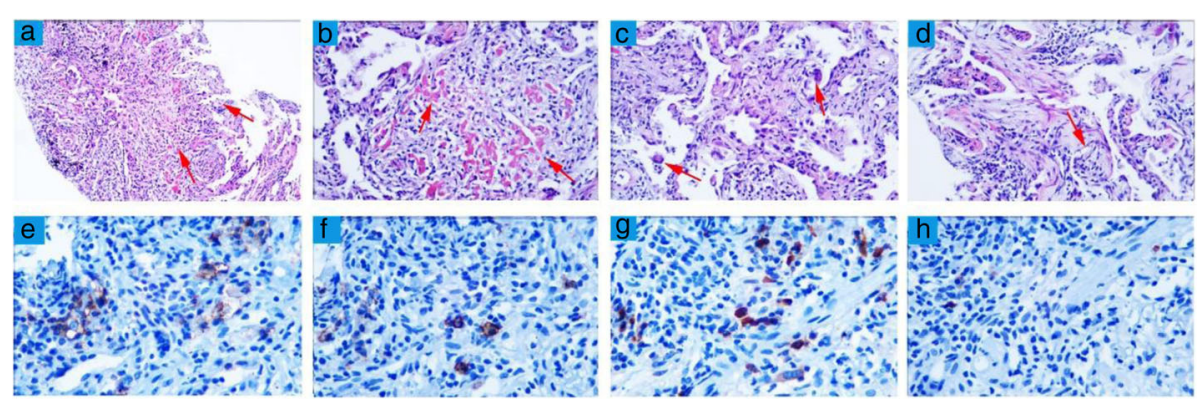

Fig. 4 Histopathological findings of the pulmonary tissue (light microscopy: HE). a Pulmonary tissue shows fibrotic changes of the interstitium ( $\times$ $100)$ in the lung. $\mathbf{b}$ Cell and tissue reactions and cellulosic exudation were observed in alveoli $(\times 200)$. $\mathbf{c}$, $\mathbf{d}$ Giant cell, interstitial edema, collagen fiber hyperplasia and masson body were observed in the specimen $(\times 200)$. e, f Immunohistological analysis revealed CD38-positive plasmacyte (coloured brown) $(E \times 400)$ and CD138-positive plasmacyte (coloured brown) infiltration ( $F \times 400)$. g lgG immunostaining shows lgG-positive plasmacyte (coloured brown) infiltration $(\times 400)$. h IgG4 immunostaining shows lgG4-positive plasmacyte (coloured brown) infiltration in the lung $(\times 400)$ 


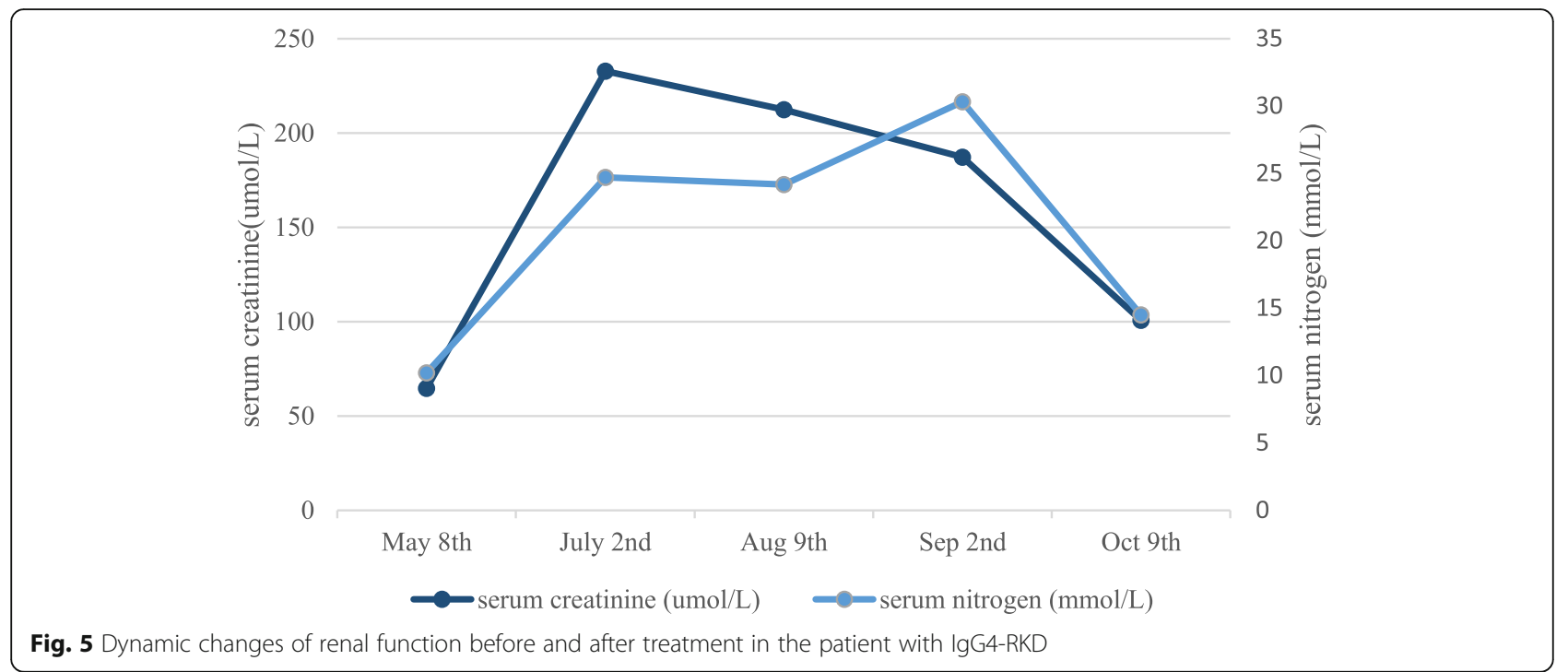

was the GGO type. This also was the primary feature of IPFI [34] of which most common chest CT signs are nodules, consolidation and GGO. This patient had several high-risk factors of IPFI such as old age, long-term use of glucocorticoids, repeated hospitalization, etc. [35]. However,it is difficult to distinguish between IgG4related lung disease (IgG4-RLD) and IPFI (Table 3). Lung puncture pathology is key standard. Thus, sputum culture and pathogenic examination were repeated and infiltration of IgG4-positive plasma cells was not found. The lung tissue specimen showed fungal spores which supported the diagnosis of IPFI. The differential diagnosis of IgG4-RLD and IPFI were listed in Table 4 [34, 36, 37].

Systemic glucocorticoids are recommended as the first-line approach of renal injury in untreated IgG4-RD [31]. A moderate initial dose of oral prednisolone for induction is $0.6 \mathrm{mg} / \mathrm{kg}$ daily for $2-4$ weeks. The maintenance dose of steroid therapy is given after remission as $2.5-5 \mathrm{mg}$ daily over a period of 2-3 months [2]. However, treatment with exogenous glucocorticoids comes with a number of risks such as avascular necrosis, osteoporosis, glaucoma, cardiovascular disease, worse glucose tolerance and diabetes. The risk of infection is of utmost concern and is well-documented [36, 38]. A Japanese study including 459 AIP patients reported pneumonia occurred in 3 patients treated with steroid [13]. Optimizing the nutritional state of patients, reducing its dose, duration and number of immunosuppressants are recommended to help prevent infection. In the present case, we have to decrease the dosage of immunosuppressive drugs after then, nevertheless, IgG4-RLD were aggravated and renal failure developed during dosage decrease.

Since not every patient can be recover from renal disfunction, maintenance hemodialysis become necessary in patients with irreversible renal failure due to IgG4-RKD [4, 39]. And in this case, the patient experienced a short-time hemodialysis because of azotemia, which partly due to deteriorating renal function, steroids use or (and) infection. Improvements in pulmonary lesions and kidney function were observed after 4 months and were maintained with a dose of $8.0 \mathrm{mg} /$ day prednisone. Thus, the dosage of steroid and immunosuppressant should be reduced for the therapy of the elderly patients with IgG4 related diseases. In addition, it has been reported that relapse of IgG4-related lesions, including kidney damage, occurred in $20 \%$ of treated patients with IgG4-RKD during maintenance treatment [39]. Thus, long-term follow-up for this patient are required and a well prognosis is expected.

Table 3 Proposed diagnostic criteria for kidney involvement in AAV [16]

\begin{tabular}{ll}
\hline clinical & a rapidly progressive GN with a decline in kidney function accompanied by sub-nephrotic-range proteinuria, microscopic \\
manifestations & hematuria, and hypertension over days to a few months \\
Serology & Anti-MPO antibody or anti-PR3 antibody positive \\
Pathological & pauci-immune focal necrotizing crescentic GN \\
findings & Rare patients with AAV have a prominent tubulointerstitial nephritis, which can be associated with vasculitis of the vasa recta \\
\hline
\end{tabular}

A diagnosis of AAV incorporates the integration of clinical features, ANCA serology, and tissue pathology as needed 
Table 4 Differences between IgG4-RLD and IPFI [34, 36, 37]

\begin{tabular}{|c|c|c|}
\hline Items & IgG4-RLD & IPFI \\
\hline $\begin{array}{l}\text { Clinical } \\
\text { manifestations }\end{array}$ & multi-system injuries & dry cough and fever, no specific \\
\hline Laboratory tests & Serum IgG4 elevation & CRP and (or) PCT elevation, G/GM positive \\
\hline Imaging & $\begin{array}{l}\text { nodules, multiple ground glass opacities (GGO),alveolar interstitial } \\
\text { type, and bronchovascular type }\end{array}$ & nodules, consolidation and ground-glass opacity(GGO) \\
\hline Pathology & $\begin{array}{l}\text { Mainly lgG4 } \\
\text { With plasma cell infiltration and often with interstitial damage }\end{array}$ & $\begin{array}{l}\text { fungal spores with hyphae can be observed, pulmonary } \\
\text { fibrosis and inflammatory cell infiltration }\end{array}$ \\
\hline $\begin{array}{l}\text { Treatment } \\
\text { protocol }\end{array}$ & Systemic glucocorticoids & anti-infection \\
\hline
\end{tabular}

Taken together, IgG4-RKD is an immune-mediated condition that can affect not only kidney but also several other organs, leading to a dense lymphoplasmacytic infiltration dominant in IgG4-positive plasma cells with fibrosis. This case should inspire clinicians to identify IgG4-related lung disease and secondary pulmonary infection, pay attention to the complications during immunosuppressive therapy for primary disease control (Fig. 6).

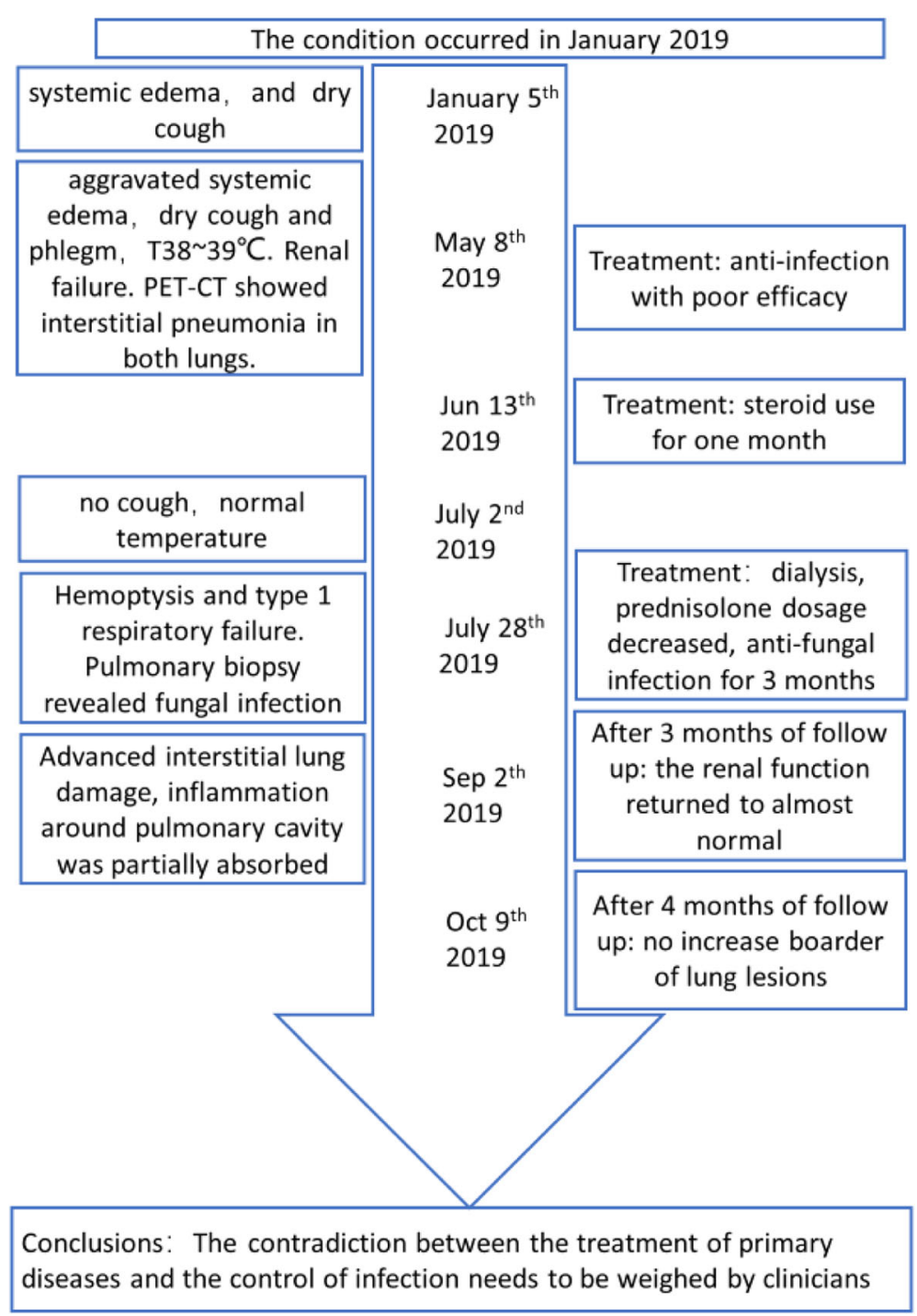

Fig. 6 Flow diagram of the patient's disease progression and treatment 


\section{Abbreviations}

IgG4-RKD: IgG4-related kidney disease; AIP: Autoimmune pancreatitis; IgG4TIN: IgG4-related tubulointerstitial nephritis; IPFI: Invasive pulmonary fungal infection; CT: Chest computed tomography; uPCR: Urine protein: creatine ratio; IgG: Serum immunoglobulin G; CTX: Cyclophosphamide; MPOANCA: Anti-myeloperoxidase anti-neutrophil cytoplasmic antibody; ANCAAAV: Anti-neutrophil cytoplasmic antibody associated vasculitis; GGO: Multiple ground glass opacities; IgG4-RLD: IgG4-related lung disease

\section{Acknowledgements}

We sincerely thank the Department of Pathology, Jiangsu province Hospital, for pulmonary pathology.

\section{Authors' contributions}

$Y L X$ reviewed the patient's clinical data, performed the literature search, and wrote the initial draft of the manuscript. $\mathrm{YYH}$ and $\mathrm{KL}$ assisted in the preparation of the manuscript contributed to data collection and interpretation and critically reviewed the manuscript. JQ, and JFZ provide the pathology of renal biopsy. XFZ performed the immunohistochemical studies. TFY conducted pulmonary puncture and provide the possibility of lung pathology. GY and XQX carried out analysis of patient's clinical course, outcomes and interpretation of findings, and provided critical review comments for the manuscript. NNW and CYX had the idea for this case report, and carried out analysis of patient's clinical course, outcomes, and interpretation of findings, and provided critical review comments for the manuscript. All authors read and approved the final manuscript.

\section{Funding}

The research was financially supported by the National Natural Science Foundation of China (81570666), International Society of Nephrology (ISN) Clinical Research Program (18-01-0247), Jiangsu Province Key Medical Personnel Project (ZDRCA2016002). The funders had the idea for this case report, and carried out analysis of patient's clinical course, outcomes, and interpretation of findings, provided critical review comments and also submission for the manuscript.

\section{Availability of data and materials}

The datasets used during the current study available from the corresponding author on reasonable request.

\section{Ethics approval and consent to participate}

Not applicable.

\section{Consent for publication}

Written informed consent was obtained from the patient for publication of this case report and any accompanying images. A copy of the written consent is available for review by the Editor of this journal.

\section{Competing interests}

The authors declare that they have no competing interests.

\section{Author details}

'Department of Nephrology, the First Affiliated Hospital with Nanjing Medical University, Jiangsu Province Hospital, Nanjing, China. ${ }^{2}$ Department of Imaging, the First Affiliated Hospital with Nanjing Medical University, Jiangsu Province Hospital, Nanjing, China.

\section{Received: 27 August 2020 Accepted: 23 December 2020}

\section{Published online: 11 January 202}

\section{References}

1. Hamano $\mathrm{H}$, et al. High serum lgG4 concentrations in patients with sclerosing pancreatitis. N Engl J Med. 2001;344(10):732-8

2. Kamisawa T, Okazaki K. Diagnosis and Treatment of lgG4-Related Disease. Curr Top Microbiol Immunol. 2017;401:19-33.

3. Morales AT, et al. An update on IgG4-related lung disease. Eur J Intern Med. 2019;66:18-24

4. Saeki T, et al. Clinicopathological characteristics of patients with lgG4related tubulointerstitial nephritis. Kidney Int. 2010;78(10):1016-23.
5. Dhobale $\mathrm{S}$, et al. IgG4 related sclerosing disease with multiple organ involvements and response to corticosteroid treatment. J Clin Rheumatol. 2009;15(7):354-7.

6. Higashioka K, et al. A Case of Immunoglobulin G4-Related Disease with Extensive Multiorgan Involvements. Case Rep Rheumatol. 2015;2015:392893.

7. Raissian $Y$, et al. Diagnosis of IgG4-related tubulointerstitial nephritis. J Am Soc Nephrol. 2011;22(7):1343-52.

8. Lin W, et al. Clinical characteristics of immunoglobulin G4-related disease: a prospective study of 118 Chinese patients. Rheumatology. 2015;54(11): 1982-90.

9. Kawano $\mathrm{M}$, et al. Proposal for diagnostic criteria for lgG4-related kidney disease. Clin Exp Nephrol. 2011;15(5):615-26.

10. Shoji S, Nakano M, Usui Y. IgG4-related inflammatory pseudotumor of the kidney. Int J Urol. 2010;17(4):389-90.

11. Surintrspanont J, et al. IgG4-related pseudo-tumor of the kidney and multiple organ involvement mimicked malignancy. Urol Case Rep. 2019;26: 100953.

12. Adachi $\mathrm{H}$, et al. A case of IgG4-related kidney disease complicated by eosinophilic lung disease. CEN Case Rep. 2015;4(2):162-8.

13. Kamisawa T, et al. Standard steroid treatment for autoimmune pancreatitis. Gut. 2009;58(11):1504-7.

14. Saravanan M, et al. Immunoglobulin G4-related tubulointerstitial nephritis associated with interstitial pulmonary disease: Report of a case with review of literature. Indian J Nephrol. 2015;25(2):113-6.

15. Umehara $\mathrm{H}$, et al. Comprehensive diagnostic criteria for lgG4-related disease (IgG4-RD), 2011. Mod Rheumatol. 2012;22(1):21-30.

16. Jennette JC, et al. 2012 revised International Chapel Hill Consensus Conference Nomenclature of Vasculitides. Arthritis Rheum. 2013;65(1):1-11.

17. Holland M, et al. Anti-neutrophil cytoplasm antibody lgG subclasses in Wegener's granulomatosis: a possible pathogenic role for the lgG4 subclass. Clin Exp Immunol. 2004;138(1):183-92.

18. Liu LJ, et al. lgG subclass distribution, affinity of anti-myeloperoxidase antibodies in sera from patients with Wegener's granulomatosis and microscopic polyangiitis. Nephrology (Carlton). 2008;13(7):629-35.

19. Li ZY, et al. An overlap of antineutrophil cytoplasmic antibody (ANCA)associated glomerulonephritis and IgG4-related kidney disease. Clin Chim Acta. 2020;501:12-9.

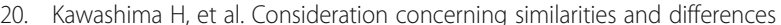
between ANCA-associated vasculitis and lgG-4-related diseases: case series and review of literature. Immunol Res. 2019:67(1):99-107.

21. Kim KP, et al. Diagnostic criteria for autoimmune chronic pancreatitis revisited. World J Gastroenterol. 2006:12(16):2487-96.

22. Uchiyama-Tanaka Y, et al. Acute tubulointerstitial nephritis associated with autoimmune-related pancreatitis. Am J Kidney Dis. 2004:43(3):e18-25.

23. Wakabayashi K, et al. Progressive Renal Dysfunction due to IgG4-Related Kidney Disease Refractory to Steroid Therapy: A Case Report. Case Rep Nephrol Dial. 2019;9(1):1-7

24. Zhang NN, et al. IgG4-related kidney disease (IgG4-RKD) with membranous nephropathy as its initial manifestation: report of one case and literature review. BMC Nephrol. 2019;20(1):263.

25. Evans R, et al. Clinical Manifestations and Long-term Outcomes of IgG4Related Kidney and Retroperitoneal Involvement in a United Kingdom IgG4Related Disease Cohort. Kidney Int Rep. 2019;4(1):48-58.

26. Zen Y, Nakanuma Y. IgG4-related disease: a cross-sectional study of 114 cases. Am J Surg Pathol. 2010;34(12):1812-9.

27. Cravedi $P$, et al. Membranous nephropathy associated with lgG4-related disease. Am J Kidney Dis. 2011;58(2):272-5.

28. Omokawa A, et al. Membranous nephropathy with monoclonal lgG4 deposits and associated lgG4-related lung disease. Clin Kidney J. 2014;7(5): 475-8.

29. Yamasue $M$, et al. Corticosteroid Therapy for a Patient with Relapsing Polychondritis Complicated by lgG4-Related Disease. Tohoku J Exp Med 2016:239(3):223-30.

30. Horita S, et al. A case of IgG4-related tubulointerstitial nephritis and membranous glomerulonephritis during the clinical course of gastric cancer: Imaging features of IgG4-related kidney disease. Mod Rheumatol. 2019:29(3):542-6.

31. Saeki T, Kawano M. IgG4-related kidney disease. Kidney Int. 2014;85(2):251-7.

32. Pandita A, Wong J. IgG4-related disease in lung: a diagnostic challenge. Pathology. 2020;52(3):390-2. 
33. Ishikawa $\mathrm{H}$, et al. IgG4-related disease in the differential diagnosis of lung nodules. Respirol Case Rep. 2020;8(4):e00550.

34. Wang J, et al. Clinical diagnostic value of spiral $C T$ in invasive pulmonary fungal infection. Exp Ther Med. 2019;17(5):4149-53.

35. $\mathrm{Mu} F \mathrm{FG}$, He HL, Li J. [Risk factors for invasive pulmonary fungal infection in children]. Zhongguo Dang Dai Er Ke Za Zhi. 2014;16(8):779-82.

36. Lionakis MS, Kontoyiannis DP. Glucocorticoids and invasive fungal infections. Lancet. 2003;362(9398):1828-38.

37. Sanguinetti $M$, et al. Diagnosis and treatment of invasive fungal infections: looking ahead. J Antimicrob Chemother. 2019;74(Suppl 2):ii27-37.

38. Youssef J, Novosad SA, Winthrop KL. Infection Risk and Safety of Corticosteroid Use. Rheum Dis Clin North Am. 2016. 42(1):157 - 76, ix-x.

39. Saeki T, et al. The clinical course of patients with IgG4-related kidney disease. Kidney Int. 2013;84(4):826-33.

\section{Publisher's Note}

Springer Nature remains neutral with regard to jurisdictional claims in published maps and institutional affiliations.

Ready to submit your research? Choose BMC and benefit from:

- fast, convenient online submission

- thorough peer review by experienced researchers in your field

- rapid publication on acceptance

- support for research data, including large and complex data types

- gold Open Access which fosters wider collaboration and increased citations

- maximum visibility for your research: over $100 \mathrm{M}$ website views per year

At $\mathrm{BMC}$, research is always in progress.

Learn more biomedcentral.com/submissions 